\title{
A AUTONOMIA DOS SUJEITOS DO CAMPO: métodos e identidades
}

Haroldo de Vasconcelos BENTES ${ }^{1}$

Instituto Federal de Educação do Pará - IFPA

haroldobentes@gmail.com

Resumo: $O$ artigo discute a autonomia dos sujeitos do campo, sob a égide da Educação do Campo, no que tange a seus protagonismos e identidades seja na Escola ou fora dela. O objetivo é sinalizar com a necessidade de centrar esforços na direção da valorização existencial desses homens e mulheres e suas produções no espaço e tempo, de forma estratégica, alargando o diálogo legítimo, global-local e vice-versa. Na linha de argumentação, duas questões: sobre os pressupostos da autonomia e legitimidade, temporalidade de saberes, memória coletiva, e suas especificidades? E a importância da relação global-local na existência daqueles, na confluência do paradigma da cientificidade e conexões com os avanços tecnológicos? A fundamentação teórica e metodológica alinha os pressupostos da dialética, cientificidade e Iniciação Científica. Nas conclusões: os sujeitos do campo precisam ser tratados como agentes políticos no processo analítico da realidade; o diálogo com conexões entre o local $e$ o global, cientificidade $e$ tecnologias como conhecimentos reconhecidos e validados; o fazer metodológico, político e epistêmico do professor promovendo novas possibilidades na aprendizagem do adulto; a iniciação científica como método que alarga e aprofunda a visão do real.

Palavras-chave: Autonomia, Educação do campo, Iniciação científica.
Abstract: The article discusses the autonomy of the subjects of the field, under the aegis of Field Education, regarding their protagonisms and identities whether in the School or outside it. The objective is to signal the need to focus efforts towards the existential valorization of these men and women and their productions in space and time, in a strategic way, broadening the legitimate, global-local dialogue and vice versa. In the line of argument, two questions: on the assumptions of autonomy and legitimacy, temporality of knowledge, collective memory, and its specificities? And the importance of the global-local relationship in the existence of those, at the confluence of the paradigm of scientificity and connections with technological advances? The theoretical and methodological foundation aligns the presuppositions of the dialectic, scientificity and Scientific Initiation. In the conclusions: the subjects of the field need to be treated as political agents in the analytical process of reality; Dialogue with connections between local and global, scientificity and technologies as recognized and validated knowledge; The methodological, political and epistemic make of the teacher promoting new possibilities in adult learning; Scientific initiation as a method that broadens and deepens the vision of reality.

Keywords: autonomy, education field, scientific initiation.

\footnotetext{
${ }^{1}$ Doutorado em Educaçãopela Universidade Federal do Ceará, UFC. Mestrado em Educaçãopela Universidade de Brasília, UnB. Professor de Filosofia no Instituto Federal de Educação do Pará (IFPA), Campus Belém.
} 


\section{INTRODUÇÃO}

A emergência formal da Educação do Campo dá-se com a publicação da Resolução 1 de 3 de abril de 2002, com as Diretrizes Operacionais para Educação Básica nas Escolas do Campo, que corroboram os pressupostos político-jurídicos previstos na Constituição Federal de 1988 e LDB 9394/1996: responsabilidade dos sistemas sob a ótica do direito; respeito às diferenças e a política de igualdade, ao proporem medidas de adequação da Escola à vida do sujeito-cidadão do campo.

Diante da legalidade formal e procedimental, pergunta-se: o que é a Educação do Campo? A interação entre o homem e o meio ambiente, e seus subsistemas, espaços da floresta, da pecuária, das minas, da agricultura, espaços pesqueiros, caiçaras, ribeirinhos e extrativistas. Portanto, fonte de ligação entre seres humanos e suas produções existências.

Historicamente, a latência do sujeito do campo por autonomia, como expressão de reconhecimento de direitos igualitários no âmbito dos seus fazeres/saberes cotidianos, está implicada nas tensões dos movimentos sociais, no Brasil, fortemente a partir dos idos anos 80, posteriormente, formalizada na Constituição de 1988, considerada símbolo maior do ideal de Estado Democrático de Direitos, pressuposto político-jurídico irradiador do exercício da cidadania plena e da justiça social, trabalho digno e sustentável, desenvolvimento social, economicamente justo e ecologicamente sustentável.

Nesse contexto, a Educação do Campo suscita desafios de toda ordem, no que tange ao protagonismo do sujeito do campo e suas identidades, seja na Escola ou na Universidade. Então, sob a perspectiva sociocultural (RICHARD HOGGART \& RAYMOND WILLIAMS, 1957. Apud. COSTA; SILVEIRA; SOMMER, 2003), pergunta-se pelos pressupostos da autonomia e legitimidade do sujeito do campo, por seus vínculos socioculturais, em geral, temporalidade de saberes; memória coletiva, e suas especificidades? Qual a importância da relação global/local hodierna na existência do homem do campo, na confluência do paradigma da cientificidade (método) e suas conexões com os avanços tecnológicos?

$\mathrm{Na}$ fronteira dessas problemáticas, apresenta-se o objetivo deste artigo: sinalizar com a necessidade de centrar esforços na direção da valorização existencial do sujeito do campo 
e suas produções no espaço e tempo, de forma estratégica, alargando o diálogo legítimo, global-local e vice-versa, com o homem/pesquisador do campo (FREIRE, 1987/1996; HABERMAS, 2003).

O processo teórico-metodológico alinha-se aos fundamentos teóricos da argumentativa dialética e ao método ${ }^{2}$ da cientificidade, através da metodologia ${ }^{3}$ da Iniciação Científica $^{4}$ com fio condutor de tese, na direção da legitimidade ${ }^{5}$ da cultura do homem do campo, como produtor/articulador de saberes locais, e ao mesmo tempo, como pesquisador de novos métodos de trabalho, conhecidos e reconhecidos pela sociedade em geral, e validados (CORBIN \&STRAUSS, 2008; RUIZ, 1991).

\section{A VALORIZAÇÃO DO SUJEITO DO CAMPO: entre o legal e o ontológico}

A valorização do sujeito do campo está legitimada por inúmeros instrumentos jurídicos.

Na linguagem política, entende-se por legalidade um atributo e um requisito do poder, daí dizer-se que um poder é legal ou age legalmente ou tem o timbre da legalidade quando é exercido no âmbito ou de conformidade com leis estabelecidas ou pelo menos aceitas (BOBBIO, 1995, p. 91).

A Constituição Federal de 1988, no Art. 205 destaca a “educação, direito de todos e dever do Estado e da família... com a colaboração da sociedade, visando o pleno desenvolvimento da pessoa $[\ldots]$...

Na direção do reconhecimento da pessoa do campo e suas práticas situadas, pelos canais da educação o Art. 206 fundamenta nos princípios norteadores do ensino que se efetive

\footnotetext{
${ }^{2}$ Um conjunto de procedimentos e técnicas para coletar e analisar dados (CORBIN; STRAUSS, 2008, p. 17).

${ }^{3}$ Uma forma de pensar sobre a realidade social e de estudá-la (IDEM).
${ }^{4}$ Processo de investigação planejada, desenvolvida e redigida de acordo com as normas da metodologia consagradas pela ciência (RUIZ, 1991).
${ }^{5}$ Em lógica, é legítimo o raciocínio quando os princípios são verdadeiros e a consequência deduzida segundo as regras. Em moral, são legítimas as ações que conformam com a razão, a equidade e a justiça universal. E finalmente, em jurisprudência são legítimas todas as ações ou omissões que as leis ordenam, etc.

MARGENS - Revista Interdisciplinar

Versão Digital - ISSN: 1982-5374
10 Anos de Margens - Dossiê: Olhares para o campo... VOL.10. N. 15. Dez2016. (p. 98-114) 
a I - igualdade de condições para o acesso e permanência na escola; e a II - liberdade de aprender, ensinar, pesquisar e divulgar o pensamento, a arte e o saber.

O Art. 214 estabelece diretrizes ao plano nacional de educação, evidenciando a essencialidade da IV - formação para o trabalho, como elemento articulador no desenvolvimento do ensino e suas interfaces formativas. E a V - promoção humanística, científica e tecnológica do País. Que dá sustentação para se refletir no âmbito dos paradigmas atuais, respectivamente, da Ciência e da Tecnologia como vetores da vida contemporânea, sobre a valorização da pessoa do sujeito do campo, e seus fazeres temporais, inseridos na lógica científica e tecnológica de nuanças local-global, que não descaracterize os fazeres e saberes dos sujeitos do campo.

Se a Constituição Federal aporta princípios, a Lei 9394 de 20/12/1996 estabelece as diretrizes e bases da educação nacional, e sob o critério da hierarquia dos mandamentos legais, o Art. 28 retoma às "[...] peculiaridades da vida rural e de cada região [...]" fortalecendo o processo de produção de conhecimento do sujeito do campo, I - conteúdos curriculares e metodologias (alternância, iniciação científica, grifo nosso) apropriadas..., II organização escolar própria..., III - adequação à natureza do trabalho na zona rural.

Em meio a recortes de realidades sob o protagonismo político dos movimentos sociais, a RESOLUÇÃO CNE/CEB 1, DE 3 DE ABRIL DE 2002, institui as Diretrizes Operacionais para a Educação Básica nas Escolas do Campo, enveredando por métodos e processos de reconhecimentos identitários dos sujeitos do campo, e de outras parajes.

No Art. $2^{\circ}$ as diretrizes se constituem conjunto de princípios e procedimentos que visam adequar o projeto institucional das escolas do campo. Desta maneira, criar a identidade da escola “[...] questões inerentes à sua realidade, ancorando-se na temporalidade e saberes próprios dos estudantes [...]".

O Art. $3^{\circ}$ destaca a responsabilidade do Poder Público como articulador estratégico no âmbito das políticas públicas “[...] o exercício da cidadania plena, o desenvolvimento de um país cujo paradigma tenhareferência na justiça social, solidariedade, diálogo, independente de sua inserção em áreas urbanas ou rurais [...]”.

MARGENS - Revista Interdisciplinar Versão Digital - ISSN: 1982-5374
10 Anos de Margens - Dossiê: Olhares para o campo... VOL.10. N. 15. Dez2016. (p. 98-114) 
Assim, destacam-se as especificidades do homem do campo e suas formas de viver e produzir conhecimento. Certo, então, é oportunizá-lo o direito de ser protagonista sociopolítico e cultural, a partir de suas escolhas e modos de perceber, problematizar a realidade, enquanto objeto de estudo, e isto não é incoerente ao método científico de pesquisar e fazer ciência.

Pois, na verdade, a relação sujeito e objeto é, a priori, condição determinante no processo de conhecer e dar significado à realidade, logo, fazer ciência não prescinde dosmodus operandi do sujeito do campo, da sua dinâmica social, ainda que o parâmetro analítico esteja ancorado nos pressupostos de uma ordem global. E nesta perspectiva, o processo de ensinar, aprender e produzir saberes/conhecimentos no campo precisa assumir uma prerrogativa dialética, através da qual fazeres, saberes e práticas revestem-se de potencialidades e possibilidades de autonomia, considerando as especificidades dos envolvidos, num diálogo contínuo, com outras realidades, processos e paradigmas.

Sob essa ótica a produção e valorização do sujeito do campo, e a constituição de sua autonomia são fortalecidas pela pedagogia da alternância e pelo processo de iniciação científica como estratégias de emancipação modi operandi, e desta forma,desconstrói-se a TESE frágil e estéril culturalmente, baseada no senso comum de que os saberes produzidos no campo carecem de capacidade de abstração, reflexão, em termos epistemológicos.

Essa percepção além de restritiva, escamoteia o diálogo entre os fazeres/saberes do campo (locais) e os métodos das ciências (globais), pois trabalha apenas no terreno da superficialidade do senso comum, desvinculando-o totalmente, como etapa processual do vir-a-ser (a mudança considerada em si mesma, como processo e passagem de um estado a outro) à episteme.

Se superficial e estaque, eliminam-se todas as possibilidades de aprender, ensinar e fazer ciência (apreensão, entendimento, compreensão e análise), pois, desqualifica-se o movimento cognoscente sobre o real (objeto de conhecimento), e assim, quebra-se a conexão entre cultura e ciência, ao se reforçar a separação entre a cultura rural e urbana, estigmatizando aquela como diferente e incomunicável, e esta como comunicável e científica. A conquista de autonomia via saberes fica restrita a uma relação de consumo, pois é este que

MARGENS - Revista Interdisciplinar Versão Digital - ISSN: 1982-5374
10 Anos de Margens - Dossiê: Olhares para o campo... VOL.10. N. 15. Dez2016. (p. 98-114) 
determina a posição social do indivíduo (HOGGART, 1957. Apud. COSTA; SILVEIRA; SOMMER, 2003).

Nessa perspectiva fragmenta-se a lógica que é única - a capacidade racional de (re) fletir, problematizar a própria ação, condição sinequa non do sujeito aprendiz, todo humano. E, de maneira equivocada, desqualifica-se o status quo da Educação do campo, que é educação construída por homens e mulheres reais. "Assim, as fronteiras de pertença a uma classe estão se transformando, à medida que a maioria dos membros de uma sociedade moderna tem cada vez mais consumos culturais comuns" (HOGGART, 1970, p. 395. Apud. DALMONTE, 999, p. 7).

Não se pode restringir o acesso ao debate de ideias diversas (pois objetos do pensar), em espaços diferentes (geográfico-culturalmente), subestimando a ideia e o espaço do outro, considerando apenas os "meus" pontos de partidas e chegadas (as teorias, os métodos da academia, das minhas leituras, etc.). Porque se neutraliza a ANTÍTESE, a ideia diversa e o espaço diferente do outro, o ser ontológico, e a potência epistemológica dele, ao desqualificar seu sistema operativo de valores, suas referências locais e, portanto, o devenir (criação e transformação), possibilidades ontocriativas de aprender, ensinar e fazer ciência.

O sujeito do campo precisa ser tratado como agente político no processo de apreensão, entendimento, compreensão e análise da realidade, da cultura a qual está vinculado. Nos estudos culturais britânicos Raymond Williams (1957) busca nas conceituações de cultura uma forma de compreender as articulações entre tentativas de dominação e resistência a partir do campo cultural. Obviamente que, do ponto de partida (e chegada)do sujeito vinculante, de seu sistema coordenativo local, sendo necessário, portanto, a devida contextualização da problemática local-global, visando suscitá-lo ao movimento pedagógico-metodológico de apreensão e análise em outras perspectivas cognoscentes.

Afinal, a natureza gnoseológica do humano não focaliza apenas realidades específicas, ao contrário, dialetiza-se nos revezes da SÍNTESE, metabolizando argumentativas criadoras, engendrando ATITUDES empáticas de respeito e solidariedade

MARGENS - Revista Interdisciplinar Versão Digital-ISSN: 1982-5374
10 Anos de Margens - Dossiê: Olhares para o campo... VOL.10. N. 15. Dez2016. (p. 98-114) 
entre aprendizes contumazes, entre homens e mulheres da cidade e do campo, da tribo, do gueto, da comunidade, etc..

O conhecimento nessa perspectiva plural, entre o local-global e vice-versa, enriquece, cria postura de civilidade, respeito mútuo pelo diverso nas ideias, ainda que, proveniente de diferentes espaços geográfico-cultural.

Atitudes nas dimensões da alteridade, no que tange à preservação da espécie humana, da racionalidade que nos distingue, fundada na ética do respeito à diversidade de hábitos, costumes, comportamentos, crenças e valores, e a aceitação da diferença no outro (UNESCO, 2009).

\section{A EDUCAÇÃO DO CAMPO: globalização, cientificidade e tecnologias}

Os desafios dos sujeitos da Educação do Campo, homens e mulheres pesquisadores, não estão desvinculados do fenômeno da globalização. A cientificidade e seus domínios tecnológicos fazem parte da vida cotidiana de todos os atores sociais, ainda que por vezes, política, econômica e ideologicamente, essas interfaces sejam (des) configuradas, diluídas por discursos excludentes e/ou "modeladas" no abstrato ou inominável, visando esvaziar o poder de participação e decisão que todos têm como direitos subjetivos na sociedade democrática.

O fenômeno da globalização reconfigura duas bases consolidadas da criatividade humana, a cientificidade e tecnologia, porém, não elimina as possibilidades de aprender, ensinar e fazer ciência (apreensão, entendimento, compreensão e análise). Assim, poder e gestão, participação e decisão são linguagens compatíveis entre o rural e o urbano, o campo e a cidade. Desta forma, alimenta-se o diálogo entre a iniciação científica e suas tecnologias, como prerrogativas identitárias implicadas nos fazeres/saberes dos sujeitos do campo no atual paradigma científico-tecnológico.

\subsection{A globalização e os reflexos na Educação do Campo}

O processo de globalização é um fenômeno do modelo capitalista que padroniza espaços, relações econômica, política, social e cultural em âmbito planetário (IANNI, 2003). Neste contexto, em geral, “a sociedade assimila um padrão de aceitação global, no qual o 
desenvolvimento tecnológico reconfigura o modo de ser, agir, se relacionar e existir dos indivíduos" (KOHN e MORAES, 2007, p. 2).

Essa reconfiguração acirra ainda mais o diálogo entre o local e o global, em termos de conhecimentos reconhecidos e validados, pois, em tese, as especificidades de fazeres/saberes de determinados segmentos sociais são apartadas do padrão global e, com muita ênfase, descaracterizadas pelos padrões cientificistas e/ou tecnológicos.

Diante disso, entende-se que a metodologia de iniciação científica nas praticas pedagógicas, em sala, e nos espaços de alternâncias, na Educação do Campo, pode funcionar muito bem como estratégia pertinente de empoderamento ${ }^{6}$ dos sujeitos envolvidos na modalidade.

De que forma? Se o trabalho com o método científico, entre professores e alunos, preponderantemente, nos momentos de alternâncias, favorecer a ampliação dos domínios teóricos, traduzidos em novas sínteses, novos modi operandi, por meio da apropriação de novas bases tecnológicas, novos processos de produção, materializados e qualificados pela integração (RAMOS, 2005) entre os fazeres/saberes específicos dos sujeitos do campo, e os fundamentos epistêmicos das ciências, e tecnologias adequadas.

E quais as etapas envolvidas nesse trabalho de integração? Os pressupostos envolvidos nos processos de integrar saberes, em geral, e seus respectivos fundamentos epistemológicos, têm como terreno fértil o aprender, ensinar e fazer ciência, constituídos pela apreensão, entendimento, compreensão e análise, sob a relação do conhecimento, sujeito e objeto.

Nessa direção, a concepção de formação integrada que subjaz ao trabalho do professor, requer deste,

[...] amarrações didático-metodológicas, ou seja, ele necessita saber integrar saberes, experiências de vida, valorizar a autoestima dos alunos, motivá-los às ações de pesquisas, procurando aproximações entre tudo isto, bem como os fundamentos dos conhecimentos considerados científicos (BENTES, 2013, P. 96).

\footnotetext{
${ }^{6}$ Empoderamento ou empowerment, em inglês, significa uma ação coletiva desenvolvida pelos indivíduos quando participam de espaços privilegiados de decisões, de consciência social dos direitos sociais (Disponível em: 〈http://www.significados.com.br/empoderamento/>. Acesso em: 22 abril 2016).
}

MARGENS - Revista Interdisciplinar

Versão Digital - ISSN: 1982-5374
10 Anos de Margens - Dossiê: Olhares para o campo... VOL.10. N. 15. Dez2016. (p. 98-114) 
Em termos de aproximações, a mediação do professor, sob a lógica da pedagogia da alternância, com foco na iniciação científica dos alunos e alunas, apreende o objeto de estudo/pesquisa em questão, na relação de conhecimento, com os sujeitos do campo, entretanto, o momento de reconhecimento do objeto não pode se desvincular das condições espaço e tempo que estão situados, e nem das implicações do objeto estudo com a realidade experiencial dos envolvidos.

Sabe-se que, em geral, na etapa de apreensão de novos conteúdos de ensino, o adulto tende a retrair-se diante de novos processos cognitivos. O baixo ou alto nível de autonomia vincula-se ao mesmo nível de curiosidade. E essa relação de proporcionalidade está diretamente ligada à habilidade do professor de articular imbricações entre os novos conteúdos/teorias e as práticas vinculantes dos sujeitos do campo (BENTES, 2013).

Dessa intrincada relação, pode-se (re) pensar a questão da autonomia daqueles nos processos de escolarização e formação profissional, e (re) planejar aulas, definir espaços pedagógicos, metodologias, etc., sabendo-se, a priori, que o adulto aprende o novo desconhecido (fazer ciência), mas também desvela outras interfaces do reconhecido (potencializa o devir, cria, recria, transforma, se transforma).

Na etapa de entendimento na fronteira do método científico, a logicidade da razão é única, a racionalidade é característica da espécie, portanto, desenvolver a capacidade reflexiva, problematizadora a partir das condições nucleares de existir como sujeitos do campo, suas especificidades produtivas e culturais, o que desperta neles a sensação de pertencimento, de poder falar de um lugar seguro e, desta maneira, criam-se antecedentes ao diálogo ético, motivacional, que fortalece as dimensões da autoestima.

No âmbito da iniciação científica (método), as intervenções professorais, revestidas por área epistêmica, alargam e aprofundam os aportes teórico-práticos, e pedagógicos dos sujeitos envolvidos. O professor como intelectual orgânico "[...] em um novo contexto de relações entre vida e cultura [...]" (GRAMSCI, 1991, p. 125).

MARGENS - Revista Interdisciplinar Versão Digital - ISSN: 1982-5374
10 Anos de Margens - Dossiê: Olhares para o campo... VOL.10. N. 15. Dez2016. (p. 98-114) 
Na etapa de compreensão, via processo de iniciação..., as características do método científico (objetividade, factualidade, rigor assertivo, etc.) devem emergir no debate de ideias e teorias sob a ótica da dialeticidade. Os procedimentos dialógicos devem ser alicerçados por métodos precisos, metodologias rigorosas nas descritivas processuais do movimento de investigação, de forma coordenada, entre tema, objeto de estudo, problema, objetivos, sem perder a focalização nos resultados almejados (hipotéticos ou aplicáveis).

Nesse devenir didático-metodológico os envolvidos (professor e alunos) são aprendizes na diversidade (procedência) e nas diferenças (valores). Assim, "[...] a diferença começa a ser vista como uma característica profunda da vida interior e não apenas uma questão de embates entre diversos grupos” (BURBULES, 2006, p. 160).

A partir desse constructo o trabalho é sistemático, e de convergência metodológica entre os pressupostos ontológicos e os epistemológicos. Constrói-se coletivamente um caminho (método) de conhecimentos integrados, mapas sobre realizadas que dialogam, a partir de problemáticas locais e globais, dialeticamente,

[...] basilares a atitude metodológica de humildade, no sentido de saber escutar sem fazer o enfrentamento de ideias e saberes, pelo menos na fase inicial do contato; e segundo, as atitudes do mediador precisam corroborar maturidade pedagógica, buscando compreender o processo de apropriação de novos saberes do adulto, com origem na iniciativa do próprio adulto. Nas etapas descritas, movimento didático, o mediador deve estimular metodologicamente o adulto a buscar o novo aprendizado, como resultante dos próprios erros, ou seja, deixar que o adulto experimente por si o enfrentamento entre o velho e o novo, o que envolve, em geral, dimensões da autoestima e automotivação.

O Art. 13 da Resolução 1 de 3 de abril de 2002, com as Diretrizes Operacionais para Educação Básica nas Escolas do Campo corrobora essa linha de raciocínio, quando se refere ao "[...] o exercício da docência nas escolas do campo, os seguintes componentes":

I - estudos a respeito da diversidade e o efetivo protagonismo das crianças, dos jovens e dos adultos do campo na construção da qualidade social da vida individual e coletiva, da região, do país e do mundo;

MARGENS - Revista Interdisciplinar Versão Digital - ISSN: 1982-5374
10 Anos de Margens - Dossiê: Olhares para o campo... VOL.10. N. 15. Dez2016. (p. 98-114) 
II - propostas pedagógicas que valorizem, na organização do ensino, a diversidade cultural e os processos de interação e transformação do campo, a gestão democrática, o acesso ao avanço científico e tecnológico e respectivas contribuições para a melhoria das condições de vida e a fidelidade aos princípios éticos que norteiam a convivência solidária e colaborativa nas sociedades democráticas.

A etapa analítica sob a égide da iniciação científica valoriza os saberes de todos os sujeitos envolvidos na Educação do Campo, os sujeitos de todas as parajes. Pois, a natureza do processo é gnoseológica, então, respeita as procedências das informações, das experiências, das histórias de vidas. E, por outro lado, enquanto um método de rigor, se propõe a validar certezas paradigmáticas; a Educação do Campo também se alinha às epistemologias.

E por que assim? Porque a capacidade de metabolizar sínteses é característica essencial do sujeito que aprende. E desta certeza indubitável, socrática "só sei que nada sei" (PLATÃO, 2010, p. 19), ou cartesiana “penso, logo existo” (DESCARTES, 1999, p.67) emerge dialeticamente a convicção axiológica que homens e mulheres envolvidos na Educação do Campo podem engendrar conhecimentos na intersecção do senso comum e da ciência (FREIRE, 1996). Conhecimento possível entre linguagens, práticas e paradigmas locais e globais, e vice-versa, através de estudos, pesquisas, projetos, com respeito mútuo pelo diverso nas ideias, ainda que, proveniente de diferentes espaços geográfico-cultural.

Na posse de um projeto assim, o adulto se vincularia a um programa de conhecimento, porque haveria uma orientação metodológica, objetivos, conteúdos, estratégias, técnicas, resultados almejados etc.. Ele se sentiria incluído, motivado, comprometido com uma proposta real de pertença, algo que lhe diz respeito nos trâmites, nas conexões, nas relações, na montagem de cenários, na direção de resultados almejados - o que, para que, por que,

\section{para quem.}

Haveria, assim, no âmago do aprendiz, uma vontade de aprender, subsumida na decisão consciente, porque se veria como um elemento parte do processo. Este adulto aprendiz entenderia a utilidade, não pragmática, da aprendizagem, mas, a utilidade como possibilidade de resolução de suas dificuldades reais, de caráter pessoal, profissional, ou de outro jaez (conjunto de traços ou características). $\mathrm{O}$ aprendiz adulto identificaria, nos 
conhecimentos estudados, ensinados e aprendidos, os recursos necessários ao seu crescimento material e intelectual, à sua felicidade.

\section{CONSIDERAÇÕES FINAIS}

São evidentes os esforços dos atores políticos da Educação do Campo na direção da valorização existencial e sociocultural dos sujeitos do campo. Historicamente e legalmente os avanços estão configurados nas políticas públicas, e nos mandamentos jurídicos.

O diálogo é interposto, de tempos em tempos, pelas tensões econômicas e políticas nas asas de um sistema de produção, que quer padronizar o consumo, e desta maneira, se serve de um viés globalizante, que evapora as especificidades de grandes segmentos sociais, sempre que estes não aglutinam ao consumo, ou destoam dos padrões ideológicos de reprodução do capital. E afirme-se, com as devidas contextualizações, utilizam-se dos avanços científicos e de ferramentas tecnológicas para materializar interesses hegemônicos (GRAMSCI, 1991).

Regra geral, o discurso globalizante fragiliza a autonomia, e a constituição de legitimidades de frações sociais, exemplo, os sujeitos do campo, quando em nome de padrões cientificistas, tecnológicos, teoréticos em demasia, legalistasnormativistas, por estas vias, esvazia-se o acesso, e despersonaliza-se o debate sobre as especificidades e modi operandi dos sujeitos do campo, e desta maneira, subtrai-se o espaço do outro, considerando apenas os "meus" pontos de partidas e chegadas (as teorias, os métodos da academia, das minhas leituras, etc.).

Diferente disso, o sujeito do campo precisa ser tratado como agente político no processo de apreensão, entendimento, compreensão e análise da realidade. Obviamente que, o seu ponto de partida (e chegada) está vinculante, em geral, ao seu sistema coordenativo local, sendo necessário, portanto, a devida contextualização da problemática local-global, visando suscitá-lo ao movimento pedagógico-metodológico de apreensão e análise em outras perspectivas.

O discurso globalizante precisa ser dialetizado, antiteticamente, a partir da relevância específica, entre o diverso e o diferente, e submetido aos revezes da SÍNTESE, entre homens

MARGENS - Revista Interdisciplinar Versão Digital - ISSN: 1982-5374
10 Anos de Margens - Dossiê: Olhares para o campo... VOL.10. N. 15. Dez2016. (p. 98-114) 
de todas as parajes: da cidade e do campo, da tribo, do gueto, da comunidade, etc.. Pois, todos são protagonistas de conhecimento na perspectiva plural, entre o local-global e viceversa, método que enriquece a civilidade, aprofunda o respeito mútuo no campo das ideias, ainda que ideias e práticas de homens e mulheres diferentes, geográfico-cultural.

Sob essa lógica, o diálogo entre o local e o global; cientificidade e tecnologias em termos de conhecimentos reconhecidos e validados no campo e na cidade podem fazer conexões. E, então, nas interlocuções da Escola, da Universidade com a Educação do Campo, via iniciação científica e pedagogia da alternância, o método científico e suas ferramentas tecnológicas servem como estratégias de empoderamento, entre os envolvidos: fazeres/saberes, métodos e ciências.

Nesse processo ontocriativo e humanizador de ampliação do conhecimento em geral, cultural, axiológico, gnoseológico, epistemológico o trabalho político, pedagógico e científico do professor é fundante na iniciação científica, preponderantemente, nos momentos de alternâncias, favorecendo a ampliação dos domínios teóricos, traduzidos em novas sínteses, novos modi operandi, por meio da apropriação de novas bases tecnológicas, novos processos de produção, materializados e qualificados pela integração entre os fazeres/saberes específicos dos sujeitos do campo, e os fundamentos epistêmicos das ciências, e tecnologias adequadas.

A metodologia científica em suas etapas de apreensão, entendimento, compreensão e análise, sob a relação do conhecimento, sujeito e objeto, integram saberes, em geral, e seus respectivos fundamentos epistemológicos, numa perspectiva fértil entre aprendizes, homens e mulheres de todos os lugares, da Escola, da Universidade, do campo e de outras procedências.

Em termos de aproximações, a mediação do professor sob a lógica da pedagogia da alternância apreende o objeto de estudo/pesquisa em questão, na relação de conhecimento, com os sujeitos do campo. E faz o reconhecimento do objeto sem desvinculá-lo das condições 
espaço-tempo que está situado, e nem das implicações do objeto com a realidade dos envolvidos.

Assim, o fazer metodológico, político e epistêmico do professor promovendo novas possibilidades no entorno da aprendizagem do adulto, este que pode aprender o novo desconhecido (fazer ciência), e mais, desvelar outras interfaces do reconhecido, isto é, o devir criativo que emerge da própria realidade justificada.

O professor, didático e pesquisador, cria dessa forma, situações reflexivas, a partir das condições nucleares do existir dos sujeitos do campo, despertando nestes a segurança de poder falar de um lugar comum; estratégia didática de imbricações entre o senso comum e outras formas de pensar o real, como objeto de aprender e ensinar. A iniciação científica emerge como método que alarga e aprofunda a visão de realidade (FREIRE, 1987).

As intersecções entre senso comum e ciência, com método, podem validar novos paradigmas entre sujeitos que trabalham na Educação do Campo. Esta outra postura de aprendizes pode engendrar dialeticamente novas linguagens comunicativas (HABERMAS, 2003), no diálogo como fundamento de uma nova ética de validade e aceitação entre os envolvidos. Portanto, práticas e paradigmas locais e globais, e vice-versa, através de estudos, pesquisas, projetos, com respeito mútuo pelo diverso nas ideias, ainda que, proveniente de diferentes espaços geográfico-cultural.

A autonomia dos sujeitos do campo emerge assim, do âmago do aprendiz, da vontade de aprender, subsumida na decisão consciente, porque se veria como elemento parte do processo.

Esse adulto compreenderia o saber formal e científico como etapas metodologias integradas, entre a sua realidade do campo e as linguagens globalizantes, sem perder de vista, as suas especificidades, como elementos que metabolizam a realidade dele, suas dificuldades reais, de caráter pessoal, profissional, ou de outro jaez. O aprendiz adulto identificaria, nos conhecimentos estudados, ensinados e aprendidos, os recursos necessários ao seu crescimento material e intelectual, à sua felicidade.

MARGENS - Revista Interdisciplinar Versão Digital - ISSN: 1982-5374
10 Anos de Margens - Dossiê: Olhares para o campo... VOL.10. N. 15. Dez2016. (p. 98-114) 


\section{REFERÊNCIAS}

ACQUAVIVA, Marcus Cláudio. Dicionário Jurídico Brasileiro. 9ª edição, Editora Jurídica Brasileira, 2014, p. 768.

BENTES, H.V. Tecnologias digitais e a prática pedagógica do PROEJA, no Instituto Federal de Educação, Ciência e Tecnologia do Pará, Campus Belém. Doutorado Universidade Federal do Ceará - Faculdade de Educação, UFC, 2013, p. 266 f. Disponívelem: <http://www.repositorio.ufc.br/handle/riufc/6039?mode=full>. Acessoem: 20 abril 2016.

BOBBIO, Norberto. Dicionário de Política. V.2, Editora UNB, 1995, p. 91.

BRASIL, Constituição da República Federativa do Brasil de 1988. Disponível em: < http://www.planalto.gov.br/ccivil_03/constituicao/constituicao.htm>. Acesso em: 22 abril 2016. Lei No 9394/1996: Diretrizes e Bases da Educação Nacional. Disponível em: <http://www.planalto.gov.br/ccivil_03/leis/L9394.htm>. Acesso em: 22 abril 2016.

. RESOLUÇÃO CNE/CEB 1, DE 3 DE ABRIL DE 2002, institui as Diretrizes Operacionais para a Educação Básica nas Escolas do Campo. Disponível em: http://www.planalto.gov.br/ccivil_03/leis/L9394.htm. Acesso em: 22 abril 2016.

BURBULES, C. Nicholas. Uma gramática da diferença: algumas formas de repensar a diferença e a diversidade como tópicos educacionais. In: CURRÍCULO NA contemporaneidade: incertezas we desafios. Regina Leite Garcia e Antonio Flavio Barbosa Moreira (orgs.). Cortez, São Paulo, 2006, p. 159/188.

CORBIN, Juliet; STRAUSS, A. Pesquisa qualitativa: técnicas e procedimentos para o desenvolvimento de teoria fundamentada. Porto Alegre: Artmed, 2008, p. 17.

COSTA, Marisa Vorraber; SILVEIRA, Rosa Hessel; SOMMER, Luis Henrique. Estudos culturais, educação e pedagogia.Rev. Bras. Educ.,Rio de Janeiro,n. 23, ago.2003. Disponível em <http://www.scielo.br/scielo.php?script=sci_arttext\&pid=S1413$24782003000200004 \& \operatorname{lng}=$ pt\&nrm=iso $>$. Acesso em 22 abril de 2016.

DESCARTES, R. Discurso do método. In. DESCARTES, Os Pensadores - Descartes. São Paulo: Nova Cultural, 1999.

FREIRE, Paulo. Pedagogia do oprimido, 17ª . ed. Rio de Janeiro, Paz e Terra, 1987.

Pedagogia da autonomia: saberes necessários à prática educativa. São Paulo: Paz e Terra, 1996 - (Coleção Leitura). 
GRAMSCI, A. Os intelectuais e a organização da cultura .Tradução de Carlos Nelson Coutinho. $8^{a}$ edição. Rio de Janeiro-RJ: CivilizaçãoBrasileira, 1991. Disponível em: <www.gepec.ufscar.br/textos-1/.../intelectuais-e-a...cultura-gramsci>. Acesso em: 23 abril 2016.

HABERMAS, Jürgen. Consciência moral e agir comunicativo . Tradução de Guido A. de Almeida. Rio de Janeiro: $2^{\circ}$ ed. Tempo Brasileiro, 2003. Disponível em: <http://www.uel.br/eventos/sepech/sumarios/temas/o_uso_da_linguagem_na_busca_compr eensiva_da_razao_na_etica_do_discurso_de_habermas.pdf $>$. Acesso em: 23 abril de 2016.

HOGGART, Richard. La culture du pauvre. Paris: Les Éditions de minuit, 1970. Apud. DALMONTE, 1999. A CULTURA POPULAR A PARTIR DOS ESTUDOS CULTURAIS BRITÂNICOS <http://www.academia.edu/8494468/A_CULTURA_POPULAR_A_PARTIR_DOS_ESTU DOS_CULTURAIS_BRIT\%C3\%82NICOS>. Acesso em: 22 abril de 2016.

IANNI, Octávio. Teorias da Globalização. 11 ed. Rio de Janeiro: CivilizaçãoBrasileira, 2003.

KOHN, K; MORAES, C. H. O impacto das novas tecnologias na sociedade: conceitos e características da Sociedade da Informação e da Sociedade Digital. Trabalho apresentado no III Intercom - Sociedade Brasileira de Estudos Interdisciplinares da Comunicação. XXX Congresso Brasileiro de Ciências da Comunicação - Santos - 29 de agosto a 2 de setembro de $2007 . \quad$ Disponível em: <http://www.intercom.org.br/papers/nacionais/2007/resumos/R1533-1.pdf >. Acesso em: 20 abril 2016.

PLATÃO: “Apologia de Sócrates, o Banquete e Fedro". $1^{\circ}$ ed. São Paulo: Folha de São Paulo, 2010 coleção livros que mudaram o mundo. Vol 05.

RAMOS, Marise. CIAVATTA, Maria. FRIGOTTO, Gaudêncio. (orgs.). Possibilidades e desafios na organização do currículo integrado. In: Ensino Médio Integrado: concepções e contradições. Gaudêncio Frigotto, Maria Ciavatta, Marise Ramos (orgs.). - São Paulo: Cortez, 2005.

RUIZ, J. A. Metodologia científica: guia para eficiência nos estudos.3 ed. São Paulo: Atlas, 1991.

UNESCO (2009) Relatório Mundial da UNESCO. Investir na diversidade cultural e no diálogo intercultural. Disponível em: <http://unesdoc.unesco.org/images/0018/001847/184755POR.pdf>. Acesso em: 22 abril de 2016. 
Pesquisa na internet:

Blogsignificados. Disponível em: 〈http://www.significados.com.br/empoderamento/>. Acesso em: 22 abril 2016.

MARGENS - Revista Interdisciplinar

Versão Digital-ISSN: 1982-5374
10 Anos de Margens - Dossiê: Olhares para o campo... VOL.10. N. 15. Dez2016. (p. 98-114) 